\title{
Advances in diagnostic practices affect thyroid cancer incidence in France
}

L Leenhardt $^{1,2}$, M O Bernier ${ }^{2}$, M H Boin-Pineau ${ }^{3}$, B Conte Devolx ${ }^{4}$, R Maréchaud $^{5}, \mathrm{P} \mathrm{Niccoli-Sire}^{3}$, M Nocaudie $^{6}$, $\mathrm{J} \mathrm{Orgiazzi}^{7}$, M Schlumberger ${ }^{8}$, J L Wémeau ${ }^{9}$, L Chérié-Challine ${ }^{1}$ and F De Vathaire ${ }^{10}$

${ }^{1}$ Institut National de Veille Sanitaire, Saint Maurice, ${ }^{2}$ Service de Médecine Nucléaire, Groupe Hospitalier Pitié-Salpétrière, ${ }^{3}$ Service de Médecine Nucléaire, CHU Poitiers, ${ }^{4}$ Service d'Endocrinologie-Diabétologie-Métabolisme, Hôpital de la Timone CHU Marseille, ${ }^{5}$ Service de Médecine Interne, CHU Poitiers, ${ }^{6}$ Service de Médecine Nucléaire, CHU Lille, ${ }^{7}$ Service d'Endocrinologie-Diabétologie-Métabolisme, Hôpital Lyon-Sud, ${ }^{8}$ Service de Médecine Nucléaire, Institut Gustave Roussy Villejuif, ${ }^{9}$ Service d'Endocrinologie-Diabétologie-Métabolisme, USNA CHU Lille, ${ }^{10}$ Unité INSERM U 521 Epidémiologie des cancers, Institut Gustave Roussy, Villejuif, France.

(Correspondence should be addressed to L Leenhardt; Email: laurence.leenhardt@psl.ap-hop-paris.fr)

\begin{abstract}
Objective: To analyse trends in diagnostic practices of thyroid diseases and to relate them to the increase in thyroid cancer incidence in France over time.

Design: From 1980 to 2000, a French retrospective multicentric (three endocrinology and three nuclear medicine centres) study of thyroid diseases was conducted on 20 consecutive unselected patients' records, sampled every 5 years in each centre.

Methods: Characteristics of the population and diagnosis procedures (thyroid ultrasonography (US), radionuclide scan, cytology and hormonal measurements) were described over time. Changing trends in operated patients and in cancer prevalence were analysed as well as the impact of practices on cancer incidence.

Results: The study included 471 patients ( $82 \%$ female, mean age 46.7 , range $9-84$ years), referred for nodular thyroid diseases $(66.7 \%$ ) or thyroid dysfunctions (33.3\%). A significant increase in US (3 to $84.8 \%$ ) and cytological practices ( 4.5 to $23 \%$ ), and a decrease $(89.4$ to $49.6 \%$ ) in radionuclide scan procedures were observed over time. Although the proportion of patients undergoing surgery remained constant $(24.8 \%)$, the prevalence of cancer increased among operated patients from 12.5 to $37 \%(P=0.006)$. In a Cox's proportional hazard model stratified on the clinical characteristics of patients, only the cytological practice, regardless of its results, was significantly associated with the occurrence of cancer: relative risk $(\mathrm{RR})=4.4$ (95\% confidence interval $(\mathrm{CI})$ : 1.1-16; $P=0.04)$.

Conclusions: From 1980 to 2000, a major evolution in clinical practices has led to the increase in thyroid cancer reported in France. Such changes in medical, as well as in surgical and pathological, practices must be taken into account in incidence measurement.
\end{abstract}

European Journal of Endocrinology 150 133-139

\section{Introduction}

Over the last two decades, thyroid cancer incidence has increased in several countries including France $(1-5)$. Several factors have been proposed as explanations for this increase, especially changes in diagnostic medical practices as well as in surgical and pathological ones (6). Indeed, the spread of new and more sophisticated diagnostic techniques such as ultrasonography (US) and fine needle aspiration biopsy (FNAB) has altered the management of thyroid diseases over time $(7,8)$. How these changes in medical practices have contributed to the increase in incidence of thyroid cancer has never been studied rigorously. This study aimed to address this specific issue in France.

\section{Materials and methods}

We carried out a retrospective multicentric study for the past two decades in six hospital centres distributed throughout France (three Departments of Endocrinology located in Lille, Marseille and Lyon and three Departments of Nuclear Medicine located in Paris, Villejuif and Poitiers). From 1980 to 2000, at 5-year intervals, 20 consecutive unselected patients' records were sampled from January 1st onwards, in each centre. The cases were patients referred for the first time for thyroid diseases (nodular thyroid diseases, thyroid dysfunctions) to each department.

In each centre, data were provided by medical record analysis. Age, gender, nature of referral (primary care 
physicians, endocrinologists, surgeons, gynaecologists or other specialists) were recorded as well as the reason for undergoing evaluation of thyroid function. For patients subjected to surgery, the possible presence of a thyroid cancer based on histology analysis was recorded. All imaging (thyroid US, radionuclide scan), cytological (FNAB) and laboratory (thyrotropin (TSH), free thyroxine (T4) and triiodothyronine (T3)) studies ordered by each physician since the first detection of thyroid abnormalities were listed and numbered. Patients presenting a history of thyroid carcinoma were excluded. In two centres (Lille and Marseille), retrospective study of medical records was only available from 1990 onwards.

In all cases, information was available from medical records for 471 patients. In Lyon, only thyroid nodular diseases were included. Thus, patients from this centre were included in the analysis of the description of the medical practices, but excluded from the study of the influence of these practices on the clinical outcomes. A total of $117(24.8 \%)$ patients had been referred for surgery.

\section{Statistical analysis}

Because this study included a defined number of patients per period and per centre, we were unable to evaluate the true variations of the incidence of thyroid nodule and cancer. In addition, because the centres included were arbitrarily chosen, we aimed not to estimate the absolute frequency of medical practices and of thyroid diseases in France, but to study their relative variations over time.

In contrast, because the selection criteria of patients in a given centre were the same for various periods of consultation, we aimed to study the variations in medical practices and in thyroid diseases among referred patients, as well as the relation between the variations in medical practice and the observed frequency of thyroid cancer. Since the number of patients included in each centre could vary with time, all the analyses had to be stratified on the centre.

Characteristics of the population, prevalence and time trends of diagnosis procedures were recorded over the last two decades and tested using $\chi^{2}$ test. The results of the US, FNAB examinations and radionuclide scans have not been collected and therefore were not taken into account in the analysis. Time trends of the proportion of patients subjected to various medical practices and of patients affected by a thyroid cancer were analysed, controlling for variables such as centre and/or referral reason.

The data analysis of the impact of medical practices on thyroid cancer incidence following consultation was based on methods of survival analysis, using Cox's proportional hazard model. We considered initial time as the date of the first examination. Final time was defined as either the date of thyroid surgery or the date of last consultation from non-operated patients (censored cases). All calculations were made with a $5 \%$ significance level, in a two-sided hypothesis.

\section{Results \\ Characteristics and evolution of the population (Table 1)}

Gender and mean age of the population corresponding to the patients' records are listed in Table 1 . The proportion of women significantly increased from 74.2 to $92.1 \% \quad(P=0.005)$, except in 2000. This significant temporal trend observed over the years persisted even after controlling for referral reason and for the centre (0.009). The mean age of patients at initial referral did not significantly differ over the course of the study, after controlling for the centre $(47.5 \pm 13.7$ vs $44.9 \pm 16.4)(P=0.3)$. No significant trend was observed in the proportion of referred patients according to the nature of referral physician (primary care physicians vs specialists) $(P=0.2$; Table 1).

\section{Reasons for referral}

Referral patterns were classified as thyroid dysfunctions (hypo- or hyperthyroidism) or nodular thyroid diseases including nodules detected incidentally through imaging (ultrasound, computer tomography (CT) scan or X-ray) (Table 1). Thyroid nodule was the main reason for referral in 295 patients $(66.7 \%)$. Despite a slight increase over the course of 20 years, the proportion of patients presenting nodular thyroid pathology did not significantly increase, when controlling for the centre $(P=0.04)$. The proportion of patients with thyroid dysfunction remained at the same level (Table 1). However, over the period, the proportion of patients with incidentally detected thyroid nodules significantly increased from 2.5 to $8.6 \%$ of patients with thyroid nodules $(P=0.007)$ (Table 1$)$.

\section{Physical examination}

Thyroid palpation was normal in 111 (24\%) patients and detected a thyroid nodule in 146 patients $(31.7 \%)$. Time trend proportions of such physical findings did not significantly differ with time when controlling for the centre $(P=0.13)$.

\section{Characteristics and time trends of diagnosis procedures}

During the period covered by this study, patients were subjected to various medical diagnostic procedures as listed in Table 2. Unsurprisingly, the proportion of radionuclide scans was higher in nuclear medicine departments than in endocrine departments 
Table 1 Evolution of the characteristics of the population.

\begin{tabular}{|c|c|c|c|c|c|c|c|}
\hline & 1980 & 1985 & 1990 & 1995 & 2000 & Total & $P$ value* \\
\hline Number of referred patients & 66 & 71 & 107 & 114 & 113 & 471 & \\
\hline Nuclear medicine & 59 & 60 & 71 & 67 & 66 & 323 & \\
\hline Endocrinology ${ }^{\mathrm{a}}$ & 7 & 11 & 36 & 47 & 47 & 148 & \\
\hline \multicolumn{8}{|l|}{ Sex } \\
\hline Males (\%) & $17(25.8)$ & $15(21.1)$ & $17(15.9)$ & $9(7.9)$ & $26(23)$ & $84(17.8)$ & $0.005^{\mathrm{b}}$ \\
\hline Females (\%) & 49 (74.2) & 56 (78.9) & $90(84.1)$ & $105(92.1)$ & $87(77)$ & 387 (82.2) & \\
\hline Mean age \pm S.D. & $44.9 \pm 16.4$ & $43.4 \pm 16.1$ & $48.1 \pm 16.3$ & $47.4 \pm 15.4$ & $47.5 \pm 13.7$ & $46.7 \pm 15.5$ & 0.3 \\
\hline \multicolumn{8}{|l|}{ Referral nature } \\
\hline Missing & 7 & 13 & 10 & 14 & 14 & 58 & \\
\hline Primary care physicians (\%) & $19(33.2)$ & $32(55.2)$ & $68(70.1)$ & $68(68)$ & $58(59)$ & 245 & 0.2 \\
\hline Specialists (\%) & $40(67.8)$ & $26(44.8)$ & $29(29.9)$ & $32(32)$ & $41(41)$ & 168 & \\
\hline \multicolumn{8}{|l|}{ Referral reason } \\
\hline Missing & 4 & 10 & 3 & 4 & 8 & 29 & \\
\hline Nodular thyroid pathology (\%) & $40(64.5)$ & $41(67.2)$ & $69(66.3)$ & $75(68.2)$ & $70(66.7)$ & $295(66.7)$ & 0.04 \\
\hline Goitre & 17 & 20 & 39 & 27 & 18 & 121 & \\
\hline Nodule & 21 & 22 & 28 & 34 & 33 & 138 & \\
\hline Multinodular goitre & 4 & 2 & 12 & 14 & 20 & 52 & \\
\hline Cervical lymph nodes & 0 & 0 & 2 & 1 & 1 & 4 & \\
\hline Cervical discomfort & 1 & 1 & 4 & 9 & 5 & 20 & \\
\hline Incidental imaging detection of nodule & 1 & 0 & 1 & 5 & 6 & 13 & 0.007 \\
\hline Thyroid dysfunction (\%) & $22(35.5)$ & $20(32.8)$ & $35(33.7)$ & $35(31.8)$ & $35(33.3)$ & 147 (33.3) & \\
\hline Hypothyroidism & 7 & 4 & 12 & 17 & 15 & 55 & 0.56 \\
\hline Hyperthyroidism & 15 & 16 & 23 & 18 & 20 & 92 & 0.07 \\
\hline \multicolumn{8}{|l|}{ Physical examination } \\
\hline Missing & 3 & 1 & 2 & 0 & 5 & 11 & \\
\hline Normal palpation (\%) & $18(28.6)$ & $20(28.6)$ & $17(16.2)$ & $25(21.9)$ & $31(28.7)$ & $111(24)$ & \\
\hline Palpable nodule (\%) & $25(39.7)$ & $25(35.7)$ & $32(30.5)$ & $34(29.8)$ & $30(27.8)$ & $146(31.7)$ & 0.13 \\
\hline Homogeneous goitre (\%) & $13(20.6)$ & $17(24.3)$ & $21(20)$ & $24(21)$ & $16(14.8)$ & $91(19.8)$ & \\
\hline Multinodular goitre (\%) & $7(11.1)$ & $8(11.4)$ & $34(32.4)$ & $31(27.2)$ & $29(26.9)$ & $109(23.7)$ & \\
\hline Cervical lymph nodes (\%) & $0(0)$ & $0(0)$ & $1(0.9)$ & $0(0)$ & $2(1.8)$ & $3(0.8)$ & \\
\hline
\end{tabular}

* Mantel-Haenszel $\chi^{2}$ trend test, stratified on the centre.

${ }^{a}$ In two centres of endocrinology, retrospective study of medical records was only available from 1990 onwards.

${ }^{b}$ Year 2000 excluded.

$(P<0.0001)$. US was widely prescribed in both types of department. FNAB was more often performed on patients referred to departments of endocrinology than those referred to nuclear medicine departments $(P=0.0002)$. Within the series, 92 patients were subjected to both US and FNAB study. The prescription rate of thyroid scintigraphy decreased significantly from $89.4 \%$ in 1980 to $49.6 \%$ in $2000(P<0.0001)$ (Table 3).

In contrast, the proportion of patients in whom US and FNAB had been performed increased significantly over the same period from 3 to $84.8 \%$ and from 4.5 to $23 \%$ respectively (Table 3 ). Of the patients with thyroid nodules, $8,39,19,42$ and $36 \%$ were subjected to FNAB

Table 2 Distribution of the medical practices according to the nature of the department.

\begin{tabular}{lcccc}
\hline $\begin{array}{l}\text { Number of assessed } \\
\text { practices (\%) }\end{array}$ & $\begin{array}{c}\text { Nuclear medicine } \\
\text { departments }\end{array}$ & $\begin{array}{c}\text { Endocrine } \\
\text { departments }\end{array}$ & Total & $\boldsymbol{P}$ value \\
\hline $\begin{array}{l}\text { Scintigraphy } \\
\text { Missing }\end{array}$ & 5 & 0 & 5 & \\
Yes & $275(86.5)$ & $69(46.6)$ & 344 & $<0.0001$ \\
No & $43(13.5)$ & $79(53.4)$ & 122 & \\
Ultrasonography & 15 & 7 & 22 & \\
$\quad$ Missing & $199(64.6)$ & $102(72.3)$ & 301 & 0.27 \\
Yes & $109(35.4)$ & $39(27.7)$ & 148 & \\
No & $50(15.5)$ & $45(30.4)$ & 95 & 0.0002 \\
FNAB & $273(84.5)$ & $103(69.6)$ & 376 & \\
Yes & 12 & 2 & 14 & \\
No & $287(92.3)$ & $146(100)$ & 433 & 0.0009 \\
Biological thyroid tests & $24(7.7)$ & 0 & 24 & \\
$\quad$ Missing & & & \\
Yes & & & \\
No & & &
\end{tabular}


Table 3 Changes in medical practices after controlling for centre.

\begin{tabular}{|c|c|c|c|c|c|c|c|}
\hline Number of assessed practices (\%) & 1980 & 1985 & 1990 & 1995 & 2000 & Total & $P$ value* \\
\hline \multicolumn{8}{|l|}{ Scintigraphy } \\
\hline Missing & 0 & 1 & 1 & 1 & 2 & 5 & \multirow{3}{*}{$<0.0001$} \\
\hline Yes & $59(89.4)$ & $62(88.6)$ & $90(84.9)$ & $78(69)$ & $55(49.6)$ & 344 & \\
\hline No & $7(10.6)$ & $8(11.4)$ & $16(15.1)$ & $35(31)$ & $56(50.4)$ & 122 & \\
\hline \multicolumn{8}{|l|}{ Ultrasonography } \\
\hline Missing & 1 & 1 & 15 & 4 & 1 & 22 & \multirow{3}{*}{$<0.0001$} \\
\hline Yes & $2(3)$ & $32(45.7)$ & $76(82.6)$ & 96 (87.3) & $95(84.8)$ & 301 & \\
\hline No & $63(97)$ & 38 (54.3) & $16(17.4)$ & $14(12.7)$ & $17(15.2)$ & 148 & \\
\hline \multicolumn{8}{|l|}{$F^{\prime} A B^{a}$} \\
\hline Yes & $3(4.5)$ & $18(25.3)$ & $14(13.1)$ & $34(29.8)$ & $26(23)$ & 95 & \multirow[t]{2}{*}{$<0.005$} \\
\hline No & $63(95.5)$ & $53(74.7)$ & $93(86.9)$ & $80(70.2)$ & 87 (77) & 376 & \\
\hline \multicolumn{8}{|l|}{ Biological thyroid tests } \\
\hline Missing & 1 & 4 & 3 & 4 & 2 & 14 & \multirow{3}{*}{0.4} \\
\hline Yes & 60 (92.3) & $63(94)$ & $101(97.1)$ & $106(96.4)$ & $103(92.8)$ & 433 & \\
\hline No & $5(7.7)$ & $4(6)$ & $3(2.9)$ & $4(3.6)$ & $8(7.2)$ & 24 & \\
\hline
\end{tabular}

* Mantel-Haenszel $\chi^{2}$ trend test, stratified on the centre.

${ }^{a}$ FNAB, fine needle aspiration biopsy.

in 1980, 1985 1990, 1995 and 2000 respectively $(P=0.003$ for the increase over time adjusted on centre). Most of the patients had biological thyroid tests performed with no temporal trend $(P=0.4)$.

\section{Trends in thyroid surgery and characteristics of the patients operated on}

Of the 471 patients included in the study, 117 (24.8\%) had been referred for subsequent surgery (94 women, 23 men). Patients presenting thyroid nodule(s) underwent surgery more often than those with other referral reasons ( 42 vs $17.7 \% ; P<0.0001$ ). The mean age of the patients operated on was 45.5 years (minimum 17, maximum 78 years); this was no different to nonoperated patients $(P=0.3)$ and there was no temporal change.

In this 20-year period, no change was observed in the proportion of the patients who were operated on, when controlling for the centre $(P=0.9)$. This remained true whatever the referral reason $(P=0.5)$ or the clinical findings $(P=0.8)$, or both $(P=0.6)$. More precisely, the proportion of operated patients presenting with thyroid nodules at referral or at physical examination did not change significantly over time $(P=0.6$ and 0.2 respectively) (Table 4$)$. In addition, there was no difference in the proportion of operated patients whether the charts had been collected from endocrine or nuclear medicine departments $(P=0.5)$ (Table 4). Of the 117 patients operated on, 81 $(69.2 \%)$ had sonographic examination, 96 (82.1\%) had radionuclide scans and $48(41 \%)$ had FNAB. More interesting is the proportion of patients subjected to a combination of procedures. Sonographic examination and FNAB were used in $34(29 \%)$ patients operated on, in contrast to the 83 who were subjected to neither US nor FNAB or were only subjected to one of these procedures. Sonographic and radionuclide scans were used in $66(56.4 \%)$ patients and radionuclide scan followed by FNAB was used in 38 (32.5\%) cases. In total, $25(21.4 \%)$ patients underwent all three procedures.

\section{Thyroid cancer in patients operated on and in relation to management procedures}

Of the 117 patients operated on, 21 (17.9\%; 7 men, 21 women) had a thyroid carcinoma. The mean time interval between initial referral and surgery was 15.4 months (1-108 months). The size of the cancer, available in only 17 charts, was $31.3 \pm 28.7 \mathrm{~mm}$ $120 \mathrm{~mm}$ ); two of these were microcarcinomas ( 3 and $6 \mathrm{~mm}$ ). Of the 34 patients operated on who were subjected to both US and FNAB study before surgery, 12 $(35.3 \%)$ showed a carcinoma. This proportion of cancer significantly differed from that derived from the 83 patients who were subjected to neither US nor FNAB or who were only subjected to one of these procedures $(9$ cancers, $10.8 \%)(P<0.05)$.

Of these 117 patients operated on, the proportion of carcinomas increased significantly from $12.5 \%$ in 1980 to $37 \%$ in $2000(P=0.006)$. This increase was observed in those patients with thyroid nodule(s) (Table 4). Using Cox's proportional hazard model stratified on the demographic and clinical characteristics of the patients at the time of consultation, only the FNAB test was significantly associated with the presence of cancer with an RR of 4.4 (95\% CI: $1.1-16$ : $P=0.04)$.

\section{Discussion}

In addition to the well-known risk factors of thyroid cancer such as radiation exposure, increased diagnostic activity has long been suspected to be of etiological 
Table 4 Evolution of the characteristics of operated patients (OP) and of patients with cancer diagnosis.

\begin{tabular}{|c|c|c|c|c|c|c|c|c|c|c|c|c|}
\hline & \multicolumn{2}{|c|}{1980} & \multicolumn{2}{|c|}{1985} & \multicolumn{2}{|c|}{1990} & \multicolumn{2}{|c|}{1995} & \multicolumn{2}{|c|}{2000} & \multicolumn{2}{|c|}{$P$ value ${ }^{\star}$} \\
\hline & Cancer & OP & Cancer & OP & Cancer & OP & Cancer & OP & Cancer & OP & Cancer $^{\mathrm{a}}$ & $\mathrm{OP}^{\mathrm{b}}$ \\
\hline Total (\% of operated patients) & 2 & $16(24.2)$ & 3 & $14(19.7)$ & 2 & $30(28)$ & 4 & $30(26.3)$ & 10 & $27(23.9)$ & - & - \\
\hline \multicolumn{13}{|l|}{ Sex } \\
\hline Males & 1 & 2 & 0 & 3 & 1 & 5 & 0 & 3 & 5 & 10 & 0.4 & 0.04 \\
\hline Females & 1 & 14 & 3 & 11 & 1 & 25 & 4 & 27 & 5 & 17 & & \\
\hline $\begin{array}{l}\text { Mean age } \pm \text { S.D. } \\
\text { Centre }\end{array}$ & $58 \pm 24$ & $46 \pm 15$ & $37 \pm 10$ & $42 \pm 11$ & $35 \pm 13$ & $44 \pm 15$ & $52 \pm 20$ & $46 \pm 14$ & $47 \pm 16$ & $48 \pm 14$ & $\begin{array}{l}0.6 \\
0.4\end{array}$ & $\begin{array}{l}0.9 \\
0.006\end{array}$ \\
\hline 1 & 0 & 0 & 0 & 0 & 0 & 2 & 0 & 5 & 3 & 4 & & \\
\hline 2 & 0 & 0 & 0 & 0 & 0 & 11 & 1 & 6 & 1 & 4 & & \\
\hline 3 & 0 & 5 & 1 & 1 & 1 & 2 & 1 & 2 & 2 & 3 & & \\
\hline 4 & 0 & 1 & 0 & 3 & 0 & 7 & 0 & 6 & 0 & 9 & & \\
\hline 5 & 0 & 4 & 1 & 4 & 1 & 5 & 1 & 7 & 2 & 3 & & \\
\hline 6 & 2 & 6 & 1 & 6 & 0 & 3 & 1 & 4 & 2 & 4 & & \\
\hline \multicolumn{13}{|l|}{ Nature of department } \\
\hline Nuclear medicine & 0 & 10 & 2 & 8 & 2 & 16 & 2 & 20 & 6 & 18 & 0.4 & 0.5 \\
\hline Endocrinology & 2 & 6 & 1 & 6 & 0 & 14 & 2 & 10 & 4 & 9 & & \\
\hline \multicolumn{13}{|l|}{ Referral reason } \\
\hline Missing & 0 & 0 & 0 & 2 & 0 & 0 & 0 & 0 & 0 & 3 & & \\
\hline Nodular pathology & 2 & 15 & 2 & 10 & 2 & 26 & 4 & 24 & 9 & 19 & 0.7 & 0.6 \\
\hline Thyroid dysfunction & 0 & 1 & 1 & 2 & 0 & 4 & 0 & 6 & 1 & 5 & & \\
\hline \multicolumn{13}{|l|}{ Clinical examination } \\
\hline Missing & 0 & 1 & 0 & 0 & 0 & 1 & 0 & 0 & 0 & 2 & & \\
\hline Nodular pathology & 2 & 15 & 3 & 14 & 2 & 29 & 4 & 29 & 10 & 23 & - & 0.2 \\
\hline Others & 0 & 0 & 0 & 0 & 0 & 0 & 0 & 1 & 0 & 2 & & \\
\hline
\end{tabular}

* Mantel-Haenszel $\chi^{2}$ trend test, stratified on the centre.

a $P$ value for a trend in the variation with time among the patients with cancer.

${ }^{\mathrm{b}} P$ value for a trend in the variation with time among the operated patients.

- Data not available.

importance in the observed increase of thyroid cancer incidence $(6,9,10)$. Population-based data derived from national cancer registries are useful to ascertain the impact of changes in medical practices on cancer incidence. Recently, Verkooijen et al. (6) reported that opening the clinical files of patients diagnosed with papillary thyroid cancer and retrieving information on method of diagnosis demonstrated the increase of cytological practice, with $50 \%$ of the papillary cancers diagnosed in this way. Indeed, FNAB has been recognized as the most reliable and best diagnostic tool for detection of malignancy in thyroid nodules $(7,11)$.

In fact, it is likely that the incidence and prevalence of cancer of the thyroid gland (so easy to explore) have the potential to rise continuously as detection thresholds for such cancers are lowered by advances in imaging and as preoperative selection of patients improves. It is our view that the study of the clinical files of patients with suspected thyroid disease, regardless of the diagnosis, should give relevant information, especially concerning changing trends in the surgery of thyroid diseases, data that are unavailable in cancer registries. The aim of our study was twofold. First, to illustrate changes in the characteristics of the referred population with thyroid diseases and to analyse trends in the prevalence of diagnostic procedures over time. Secondly, how such technical advances change physicians' perspectives on thyroid surgery and how they explain, at least in part, the increased prevalence of thyroid cancer in operated patients.
The arbitrary choice of the centres and the geographical discrepancies in the management of thyroid diseases related to physicians' medical customs and technical capacities of the centre, precluded an analysis of geographical variations of the prevalence of thyroid disease and thyroid cancer in France. Nevertheless, the overall similar sample selection of patients in each centre allowed us to analyse time trends of clinical characteristics of patients and medical practices as well as the relation with the presence of cancer.

In the literature, there is a lack of population-based data concerning the characteristics of the population that initially consulted for evaluation of thyroid disease. Our results show that the proportion of women referred increased over the last two decades. Two factors could explain this observation. First, women are known to be the main consumers of health care, of prescription drugs and the primary decision-makers about health care for their families (12). In fact, women are more likely than men to undergo an evaluation of thyroid function for benign causes. Moreover, as reported by Sigurdson et al.(13) workers today have easy access to health care. Secondly, thyroid diseases are more common in females (14).

More interesting was the observed trend in the referral patterns of patients and in physical findings over time. The proportion of patients referred for palpable nodular thyroid disease or for suspicion of thyroid dysfunction remained stable; this contrasts with the 
significant increase in patients referred for nodule(s) that were incidentally detected through imaging. As reported in the literature, this is probably due to the spread of thyroid gland US that increased in our series from 3 to $85 \%$ over the past two decades. In our series, patients underwent US and FNAB more frequently in endocrine departments than in nuclear medicine departments (Table 2). This result may be explained by the fact that patients are referred to the endocrinologists who are responsible for the ultimate management of patients. More interesting is that the increase in US practice over time was observed regardless of the nature of the centre to which the patient was referred and was associated with a decrease in the proportion of radionuclide scans performed. Some authors reported similar results, arguing that thyroid scans provide little information in patients who undergo FNAB (15). Such ultrasonographic changes in practices were similar to those observed in North American and European surveys, but information in these latter cases was derived from answers to a questionnaire distributed to physicians which had a poor response rate and consequently did not reflect the reality of daily practices (16). Moreover, it was not possible to study changing trends in the management of thyroid nodules in this study. In our study the marked increase in the proportion of cytological practices only reached $36 \%$ of patients with nodular disease in 2000 in France. There are two possible explanations. First, FNAB is not a procedure commonly prescribed by primary care physicians. Secondly, even among specialists, disagreements persist on the diagnostic value of FNAB, especially concerning suspicious cytological results and whether or not to operate in the presence of benign cytological findings. North American endocrinologists rely heavily on FNAB results; however, European endocrinologists, especially French ones, perform supplementary testing such as US, and will opt for surgery in cases where there are clinical or US features favouring thyroid malignancies despite benign FNAB results $(16,17)$. These results are in accordance with the study of Hölzer et al. (18) on the current patterns of care and disease characteristics for patients with thyroid carcinoma where FNAB of the thyroid is highly recommended in the current Clinical Practice Guidelines available in Germany but FNAB was performed in only $27.4 \%$ of the patients. These results emphasized the fact that diagnosis of thyroid carcinoma is often derived from a combination of US, thyroid scan or FNAB, together with clinical findings.

The design of the study allows us to conclude that the proportion of patients operated on was stable over time, when controlled for the centre. A similar result was reported by Fahey et al. (10) over a 30-year period. More precisely, in our series, this lack of increase was observed in patients presenting a nodular pathology. In this connection, it is very interesting to observe that the incidental detection of thyroid nodules, made possible by systematic imaging, did not promote an increase in the prevalence of patients undergoing surgery. Improved imaging procedures, notably US resolution, led to the detection of suspicious non-palpable nodules requiring FNAB $(19-21)$. Thus, referral patterns of thyroid nodules that required surgery have changed but the proportion of patients subjected to surgery remains stable, thanks to better preoperative selection of patients. However, the proportion of cancer among patients operated on dramatically increased from 12.5 to $37 \%$ over the same period and reached values similar to those reported in other series (10, $22,23)$. As reported by Gharib et al. (7), the percentage of patients undergoing thyroidectomy has even decreased by $25 \%$ and the yield of carcinoma in patients who undergo surgery has increased from 15 to at least $30 \%$.

Even more interesting is the analysis of the type of procedures ordered and performed and their association with the detection of thyroid cancer. Our results showed that the prevalence of cancer in operated patients subjected to both US and FNAB procedures before surgery is higher than in those who had not performed these tests. Thyroid cancer incidence analysis based on methods of survival analysis demonstrated that only FNAB, regardless of its results, was significantly associated with the presence of cancer. To the best of our knowledge, this is the first study that attempted to examine the association between changes in practice and incidence of cancer in thyroid diseases in general. As reported by some authors, the introduction of FNAB altered the referral patterns for surgery and promoted the detection of cancer (10). Nevertheless, larger studies are needed to determine whether the increased incidence of thyroid cancer is not simply the result of an altered thyroid nodule referral pattern because of FNAB, but also the result of performing more extensive surgery for multinodular goitre, thus yielding more thyroid tissue and more slides for pathologic examination and hence the increase in detection of occult papillary cancer. In our series, two of the cancers were microcarcinomas incidentally detected at pathology. Further research is also needed to elucidate the impact of changes in histological criteria. The small number of cancers observed in this study precluded us from addressing this specific question.

The present survey represents an effort to analyse the impact of changes in medical practice attitudes on the prevalence of cancer in operated patients and outlined the association between the spread of FNAB and the increase in thyroid cancer. The contribution of this management change also has to be compared with that of the surgical and pathological procedure modifications which have occurred during the last two decades in order to fully account for the observed thyroid cancer increase. 


\section{References}

1 Colonna M, Grosclaude P, Remontet L, Schvartz C, Mace-Lesech J, Velten $\mathrm{M}$ et al. Incidence of thyroid cancer in adults recorded by French cancer registries (1978-1997). European Journal of Cancer 200238 1762-1768.

2 Liu S, Semenciw R, Ugnat AM \& Mao Y. Increasing thyroid cancer incidence in Canada, 1970-1996: time trends and age-periodcohort effects. British Journal of Cancer 200185 1335-1339.

3 Akslen LA, Haldorsen T, Thoresen SO \& Glattre E. Incidence of thyroid cancer in Norway 1970-1985. Population review on time trend, sex, age, histological type and tumour stage in 2625 cases. Acta Pathologica Microbiologica et Immunologica Scandinavica $199098549-558$.

4 Franceschi S, Boyle P, Maisonneuve P, La Vecchia C, Burt AD, Kerr DJ et al. The epidemiology of thyroid carcinoma. Critical Reviews in Oncology 19934 25-52.

5 Parkin D, Whelan S, Ferlay J, Raymond L \& Young J. Cancer incidence in five continents. In IARC Scientific Publication 143. vol VII, Lyon: International Association of Cancer Registries 1997.

6 Verkooijen HM, Fioretta G, Pache JC, Franceschi S, Raymond L, Schubert $\mathrm{H}$ et al. Diagnostic changes as a reason for the increase in papillary thyroid cancer incidence in Geneva, Switzerland. Cancer Causes Control $20031413-17$.

7 Gharib H \& Goellner JR. Fine-needle aspiration biopsy of the thyroid: an appraisal. Annals of Internal Medicine $1993118282-289$.

8 Marqusee E, Benson CB, Frates MC, Doubilet PM, Larsen PR, Cibas ES et al. Usefulness of ultrasonography in the management of nodular thyroid disease. Annals of Internal Medicine 2000133 696-700.

9 Burgess JR, Dwyer T, McArdle K, Tucker P \& Shugg D. The changing incidence and spectrum of thyroid carcinoma in Tasmania (1978-1998) during a transition from iodine sufficiency to iodine deficiency. Journal of Clinical Endocrinology and Metabolism 200085 1513-1517.

10 Fahey TJ 3rd, Reeve TS \& Delbridge L. Increasing incidence and changing presentation of thyroid cancer over a 30-year period. British Journal of Surgery $1995 \mathbf{8 2} 518-520$.

11 Giard RW \& Hermans J. Use and accuracy of fine-needle aspiration cytology in histologically proven thyroid carcinoma: an audit using a national pathology database. Cancer $200090330-334$.

12 Pinn VW. Sex and gender factors in medical studies: implications for health and clinical practice. Journal of the American Medical Association 2003289 397-400.
13 Sigurdson AJ, Doody MM, Rao RS, Freedman DM, Alexander BH, Hauptmann $\mathrm{M}$ et al. Cancer incidence in the U.S. radiologic technologists health study, 1983-1998. Cancer $2003 \quad 97$ 3080-3089.

14 Wang C \& Crapo LM. The epidemiology of thyroid disease and implications for screening. Endocrinology and Metabolism Clinics of North America $1997 \mathbf{2 6} 189-218$.

15 Sabel MS, Staren ED, Gianakakis LM, Dwarakanathan S \& Prinz RA. Effectiveness of the thyroid scan in evaluation of the solitary thyroid nodule. American Surgeon 199763 660-664.

16 Bennedbaek FN \& Hegedus L. Management of the solitary thyroid nodule: results of a North American survey. Journal of Clinical Endocrinology and Metabolism 200085 2493-2498.

17 Leenhardt L, Menegaux F, Fran B, Delbot T, Mansour G, Hoang C et al. Selection of patients with solitary thyroid nodules for operation. European Journal of Surgery 2002168 236-241.

18 Hölzer S, Reiners C, Mann K, Bamberg M, Rothmund M, Dudeck J et al. Patterns of care for patients with primary differentiated carcinoma of the thyroid gland treated in Germany during 1996. U.S. and German Thyroid Cancer Group. Cancer 200089 192-201.

19 Brawley OW. Prostate carcinoma incidence and patient mortality: the effects of screening and early detection. Cancer $1997 \mathbf{8 0}$ 1857-1863.

20 Leenhardt L, Hejblum G, Franc B, Fediaevsky LD, Delbot T, Le Guillouzic D et al. Indications and limits of ultrasound-guided cytology in the management of nonpalpable thyroid nodules. Journal of Clinical Endocrinology and Metabolism 199984 24-28.

21 Papini E, Guglielmi R, Bianchini A, Crescenzi A, Taccogna S, Nardi F et al. Risk of malignancy in nonpalpable thyroid nodules: predictive value of ultrasound and color-Doppler features. Journal of Clinical Endocrinology and Metabolism 200287 1941-1946.

22 Hamberger B, Gharib H, Melton LJ 3rd, Goellner JR \& Zinsmeister AR. Fine-needle aspiration biopsy of thyroid nodules. Impact on thyroid practice and cost of care. American Journal of Medicine $198273381-384$.

23 Galloway JW, Sardi A, DeConti RW, Mitchell WT Jr \& Bolton JS. Changing trends in thyroid surgery. 38 years' experience. American Surgeon 199157 18-20.

Received 28 July 2003

Accepted 14 October 2003 